\title{
Knowledge, Attitudes, Sexual Behaviors and Utilization of Health Services among Filipino Men who have Sex with Men (MSM)
}

\author{
Jansil Marie L. Amit, ${ }^{1}$ Sarah Jane A. Jimenez, ${ }^{1}$ Carla Jane Concepcion O. Magno, ${ }^{1}$ \\ Angelico Rome Y. Andaya ${ }^{1}$ and Ofelia P. Saniel ${ }^{2}$ \\ ${ }^{1}$ Postgraduate Internship Program, University of the Philippines Manila - Philippine General Hospital \\ ${ }^{2}$ College of Public Health, University of the Philippines Manila
}

\begin{abstract}
Objectives. The main objective of this study was to describe the knowledge, attitudes, sexual practices, and utilization of health services of the MSM population in the Philippines.

Methods. The study design was cross-sectional. Data was collected through an online survey of Filipino MSMs with accounts at any of the three (3) major MSM websites. This was supplemented by focus group discussions and key-informant interviews of informal MSM leaders. Only 682 men satisfied the eligibility criteria and were included in the analysis.

Results. Forty eight percent (48\%) of the respondents had low levels of knowledge on Human Immunodeficiency Virus (HIV). Majority (54\%) engaged in unprotected sex despite having positive attitudes toward condom use. MSMs had multiple sex partnerships to satisfy their "high libido" and get "sexual gratification." Only $17 \%$ had submitted themselves for HIV testing and knew their results.
\end{abstract}

Conclusions. MSMs remain at high risk for HIV and Sexually Transmitted Infections (STI's). There is a wide gap between knowledge and actual sexual practices, and their health-seeking behavior remains poor. Thus, there is a need for programs that are tailored to the needs, cultural diversities, and unique practices of the MSM community.

Key Words: MSM, HIV, STI, knowledge, attitudes, practices

\section{Introduction}

In some parts of the world, the Acquired Immunodeficiency Syndrome (AIDS) epidemic has already spread to the general population. In the Philippines, however, the epidemic remains concentrated in groups with

Presented and won 2nd place (poster and abstract) at the UP-NIH National Health Research Forum, February 2012, Hyatt Hotel. Poster presented at the 7th Asia Pacific Conference on Reproductive and Sexual Health and Rights, January 2014, Philippine International Convention Center.

Corresponding author: Jansil Marie L. Amit, MD

Postgraduate Internship Program

University of the Philippines Manila - Philippine General Hospital

Taft Avenue, Ermita, Manila 1000 Philippines

Telephone: +632 5254239

Email: jansilamit@gmail.com known high-risk behaviours. The AIDS Registry for March 2014 lists that the total number of HIV positives has reached almost $18,000 .{ }^{1}$ Almost 9 out of 10 HIV seropositive cases are males and almost $70 \%$ reported homosexual and bisexual contact as the suspected modes of transmission.2,3 Based on the registry data, the mode of transmission of HIV shifted from mostly heterosexual for the period 1984 to 2006 to predominantly homosexual at present. 2,3,4 The current status of the HIV problem in the country presents a public health dilemma because just like female sex workers and injecting drug users, MSMs are considered a "marginalized group" in the society. The gay community is a heterogeneous community. There is too much diversity not only in terms of sexuality or self-identity but also differences in socioeconomic status, educational attainment, ethnicity, rural/urban origins, religious affiliations, age, and diversity in gay language across the various sub-cultures. ${ }^{6,7}$

Aside from the diversity of the MSM population, the prevalence of HIV and sexually transmitted infections (STI's) will continue to grow as a result of low levels of protective behaviours such as condom use and high levels of HIVrelated risk behaviours such as unprotected anal sex, multiple sex partners, drug and alcohol use, and inadequate knowledge and many misconceptions on HIV transmission and prevention. ${ }^{5}$ In addition, MSMs may potentially spread the infection to the general population, since majority of them who have unprotected sex with their male partners also have unprotected sex with their female partners. ${ }^{8}$

Because they are in the shadows, MSMs are difficult to reach with HIV/AIDS information and other health services; hence, the health-seeking behaviour of MSMs continues to be poor and frequently involves delay and concealment due to the stigma and discrimination associated with being an MSM. ${ }^{3}$ Moreover, MSMs also lack access to health services appropriate for their needs. The 2005 Integrated HIV Behavioral and Serologic Surveillance (IHBSS) of the DOH showed that only $9-41 \%$ of MSM received HIV information from outreach workers, and $11-29 \%$ received condoms or have free access to condoms. ${ }^{4}$

Although there are a number of local studies on MSMs, most of them involved only a small subset of the population. The data available are limited and unable to provide a more 


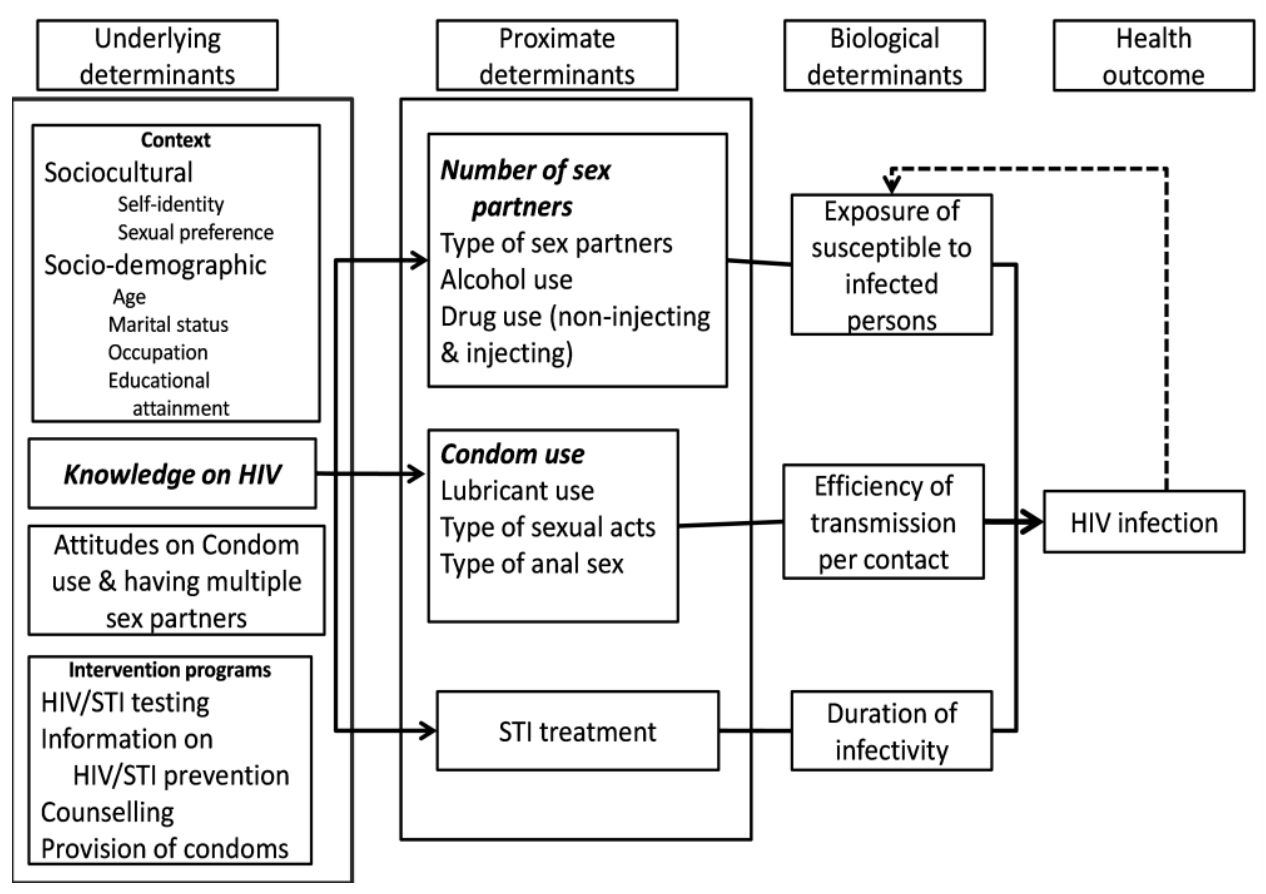

Figure 1. Research conceptual framework

in-depth assessment of the heterogeneous subgroups that comprise the MSM population across the Philippines. The main objective of the study was to describe the knowledge, attitudes, sexual practices and utilization of health services related to HIV/STI among MSMs. The relationship between these factors and how they overlap, were also examined. Moreover, to enable the researchers to access a wider crosssection of the different MSM sub-populations, an online survey was utilized..$^{9,10}$ The conceptual framework of the study is shown in Figure 1. This framework expands the scope of the study to include various levels of determinants, from the underlying, to proximate, to biological determinants. Although the present study did not collect data on the HIV status, the authors tried to relate the different determinants to the health outcome of interest, which is HIV infection.

\section{Methods}

\section{Research Design and Study Population}

The research utilized a cross-sectional study design to describe the knowledge, selected sexual practices, attitudes, and utilization of health services of the study population as they exist in the defined population at one point in time. The study population was composed of men who identify themselves as MSMs.
The inclusion criteria for the eligible population were the following: (1) A male who had experienced sex ${ }^{1}$ with a man at least once in his life; (2) a Filipino citizen; (3) at least 18 years old; (3) a current resident of the Philippines; and, (4) someone with account/s at any of the following major websites: http://planetromeo.com, http://biggermanila.org, http://singleguysmanila.ning.com. The computed sample size was 614 computed at $95 \%$ level of significance. The actual sample size was 682, which exceeded the required sample size by $11 \%$.

\section{Data Collection Methods}

A triangulation of methods was utilized: (1) keyinformant interviews (KII); (2) focus group discussions; and, (3) internet-based survey. Three (3) in-depth interviews with key-informants were conducted and the information gathered was used to design the focus group discussion guide. The key-informants were purposively chosen based on their expertise in the field of HIV/AIDS in the Philippines and their affiliation with the MSM community (TLF Share Collective Organization) and non-government organizations of MSMs. The KII's were followed by two face-to-face focus group discussions (FGDs) composed of 6-15 members from various socio-economic classes and age groups with representatives from the different subsets of the MSM population, e.g. "parloristang bakla," bisexuals, male sex workers, 'straight' men, transgenders, and transsexuals. In-

${ }^{1}$ Sex in this study is between men unless stated for both sexes. Anal sex is operationally defined as the penetration of the erect penis in the partner's anus. $^{13}$ 
depth discussions on specific topics and issues such as sexual identities and practices, attitudes towards condom use and multiple sex partnership, and current state of health programs and services for HIV/STI were used as supplementary data sources to contextualize the survey results.

The internet-based survey tool was patterned after the 2009 IHBSS interview schedule of the Department of Health. It has twelve sections pertaining to the major variables of the research. Sections on the different sexual practices such as anal sex with male partner, illicit drug use and alcohol intake which used the same time frame as the IHBSS (i.e., in the last 12 months) to standardize the survey tool and make the results comparable with other studies. The sections on attitudes were taken from the data provided by the FGDs. Pretesting of the online questionnaire was conducted with different MSM groups (e.g. "parloristang bakla," transsexuals, bisexuals), with a sample size of 10-15. A total of three to four pre-tests were conducted, online and offline. The tool was revised based on the outcome of the pre-tests. Those who participated in the pre-tests were not included in the survey.

The final version of the questionnaire was generated using an online survey software and questionnaire tool - the Survey Monkey. ${ }^{\circledR}$ To allow different respondents to participate in the study using computers with the same Internet Protocol (IP) address (e.g., respondents who participate in the survey in one location, such as a computer shop), the Survey Monkey was customized in such a way that multiple respondents were allowed per computer. However, the respondent needed to complete the survey in one sitting. The respondent was not allowed to refresh or access any part of the questionnaire once he leaves the webpage. To ensure that there were no duplicates, specifically for those with accounts at more than one website, the respondent's date of birth and the initials of his mother's name were used to screen out duplicates.

The data collection was conducted for a total period of 4 weeks. Most of the respondents were recruited from planetromeo.com website which had some 67,231 registered Filipino MSMs. The researchers created an account from which the invitations to participate, together with the survey link, were sent to all Filipino MSM members. A Philippine map and a list of members from all the provinces and cities in the Philippines were provided by the website. They were used to ensure that a representative sample of the MSM community was chosen for the study.

Other major online MSM communities in the Philippines (e.g. singleguysmanila.ning.com, biggermanila.org) were also invited to participate, through their respective webmasters and administrators. These persons served as the research team's gatekeepers to the online MSM communities. The study was endorsed by posting the survey links at the official research blog page, the homepage of the respective websites and through email blasts (i.e. sending an invitation to all the members' accounts).

\section{Data Analysis}

The data for the quantitative survey was generated from Survey Monkey. A software was used to convert the data to SPSS format. In the first part of data analysis, the respondents were analyzed based on the eligibility criteria (Figure 2) and data processing included checking the IP addresses of the computers the respondents used to exclude duplicates. For descriptive analysis, SPSS software was used. Socio-demographic characteristics and other major qualitative variables, e.g., condom use, type of partner, utilization of health services, were described in terms of frequencies and percentages. Measures of central tendency were also computed for quantitative continuous variables. The knowledge questions were analyzed using the UNGASS (United Nations General Assembly Special Session) knowledge indicators, which included two questions on misconceptions and three questions on HIV transmission and prevention. High level of knowledge was defined as having correctly answered all five knowledge questions.

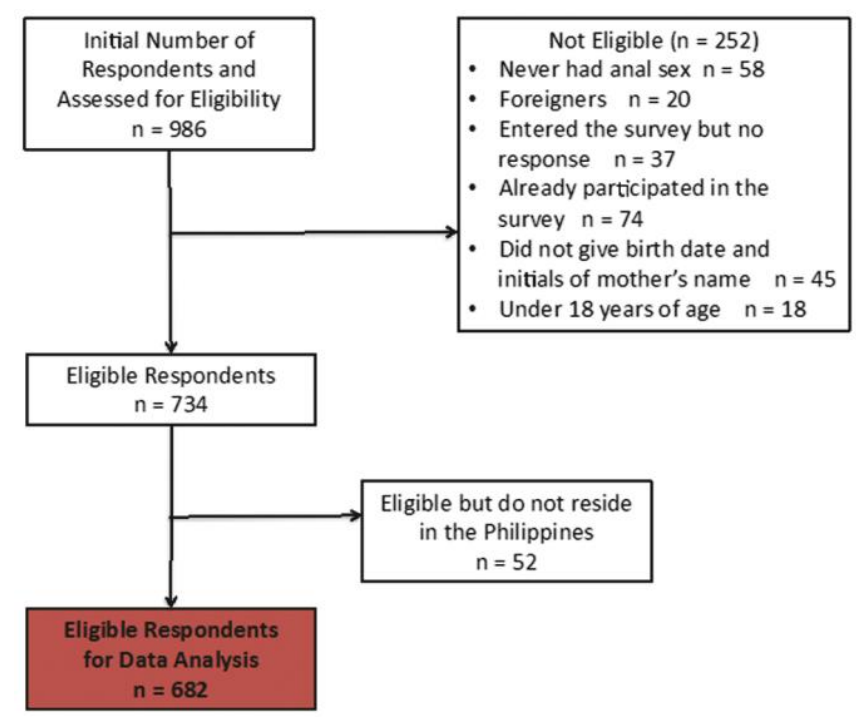

Figure 2. Data processing flow chart

\section{Ethical Considerations}

The study was submitted to the University of the Philippines - College of Public Health Ethics Committee for approval prior to conduction of data collection. The main ethical considerations in this study concerned the use of the internet to collect data since internet-mediated research uses methods that are different from the traditional methods of data collection. ${ }^{11,12}$ Although the national ethics guidelines stipulate that written informed consent is not required if the information is obtained by means of a questionnaire, as in 
this study, the investigators nevertheless obtained the informed consent of all participants of the online survey. ${ }^{21}$

An official blog site was created for the research to serve as a forum for disseminating information, and where respondents can contact the authors for additional information and for questions about the study. As no faceto-face meeting took place between participants and researchers, subjects' agreement to participate was based on a full disclosure of the purposes of the study, who the researchers were and who would have access to the data. The respondents were given the assurance that they had the right to decline to participate in the survey, to withhold answers to certain sensitive questions, and to terminate the survey anytime they wished. In addition, the administrators of each website were contacted for authorization to use the websites in the study. No personal information such as age and address were collected from the respondents. Finally, measures taken to ensure protection of the Survey Monkey database included creating an account whose account name and password were known only to the researchers; thus, access to the online database is restricted.

\section{Results}

A total of 986 Filipino MSMs from the said websites responded positively to the invitation to participate in the survey. Of the 986, some 252 did not meet the initial eligibility criteria. Of the 252, 58 had never engaged in anal sex, 20 were foreigners, 37 entered the survey but did not answer any question. 74 respondents were identified as duplicates while 45 respondents did not give the identifiers required and 18 were under-age (below 18 years old). A total of 682 respondents was included in the study.

Men surveyed online were significantly younger (mean age 26 years, $\mathrm{SD} \pm 6.96$ ), more likely to be college graduates $(80 \%)$, employed (63\%), and unmarried (90\%) (Table 1). A small proportion of men $(7 \%)$ currently live with their male partners.

Approximately $48 \%$ of the MSM respondents answered most of the UNGASS knowledge indicator questions correctly. More than half of the respondents (89\%) knew that "using condoms can reduce the risk of HIV transmission." However, a high percentage of MSMs (52\%) still have low levels of knowledge on HIV (figures not shown). Only $74 \%$ of the respondents were aware that "having sex with one faithful, uninfected partner can reduce the risk of HIV transmission." (Table 2)

Table 1. Selected demographic characteristics of the MSM study population, Philippines, 2010

\begin{tabular}{|c|c|c|}
\hline Characteristic & Number & Percent \\
\hline Total & 682 & \\
\hline \multicolumn{3}{|l|}{ Age (in years) } \\
\hline $18-25$ & 392 & 57.5 \\
\hline $26-30$ & 173 & 25.4 \\
\hline $31-35$ & 61 & 8.9 \\
\hline $36-40$ & 21 & 3.1 \\
\hline $41-45$ & 18 & 2.6 \\
\hline $46-50$ & 7 & 1.0 \\
\hline$>50$ & 10 & 1.5 \\
\hline \multicolumn{3}{|l|}{ Educational attainment } \\
\hline No schooling & 1 & 0.2 \\
\hline Elementary Graduate & 0 & 0 \\
\hline High school Graduate & 24 & 3.5 \\
\hline Technical/Vocational Training & 18 & 2.6 \\
\hline College Graduate & 545 & 79.9 \\
\hline Post-Baccalaureate & 93 & 13.6 \\
\hline No Response & 1 & 0.2 \\
\hline \multicolumn{3}{|l|}{ Occupation } \\
\hline Unemployed & 241 & 35.3 \\
\hline Employed & 429 & 62.9 \\
\hline No Response & 12 & 1.8 \\
\hline \multicolumn{3}{|l|}{ Marital status } \\
\hline Single & 617 & 90.5 \\
\hline Married & 12 & 1.8 \\
\hline \multicolumn{3}{|l|}{ Live-in } \\
\hline - $\quad$ with male partner & 47 & 6.9 \\
\hline - $\quad$ with female partner & 2 & 0.3 \\
\hline Separated & 3 & 0.4 \\
\hline No Response & 1 & 0.1 \\
\hline
\end{tabular}

On sexual identities, there was an almost equal proportion of self-identified bisexuals (48\%) and homosexuals (49\%) (Table 3). Data on sexual preference or the preferred sex of sexual partner, was also collected. More than threefourths of the respondents preferred male sex partners; only one in five MSMs preferred females as sex partners.

The mean age of MSMs at first intercourse with a man ("coital debut") was 18 years (SD \pm 5.19$)$. In the last 12 months, almost all the respondents (96\%) reportedly engaged in oral sex while three out of four MSMs (76\%) engaged in anal sex and $80 \%$ in masturbation. Only a small proportion of MSMs exclusively practiced oral sex. Most

Table 2. Distribution of respondents according to response to questions on knowledge on transmission and prevention of HIV, Philippines, 2010.

\begin{tabular}{|c|c|c|c|c|c|c|}
\hline \multirow{2}{*}{ UNGASS Indicator Questions } & \multicolumn{2}{|c|}{ Correct } & \multicolumn{2}{|c|}{ Incorrect } & \multicolumn{2}{|c|}{ No Response } \\
\hline & Freq & $\%$ & Freq & $\%$ & Freq & $\%$ \\
\hline Q1.Can having sex with one faithful, uninfected partner reduce the risk of HIV transmission? & 504 & 73.9 & 132 & 13.4 & 46 & 6.7 \\
\hline Q2. Can using condoms reduce the risk of HIV transmission? & 605 & 88.7 & 33 & 4.8 & 44 & 6.5 \\
\hline Q3. Can a healthy looking person have HIV? & 594 & 87.1 & 12 & 6.2 & 46 & 6.7 \\
\hline Q4. Can a person get HIV from mosquito bites? & 473 & 69.4 & 165 & 24.2 & 44 & 6.5 \\
\hline Q5. Can a person get HIV by sharing a meal with someone who is infected? & 544 & 79.8 & 94 & 13.8 & 44 & 6.5 \\
\hline
\end{tabular}


engaged in both oral and anal sex. During their last anal intercourse, the proportion of MSMs who claimed that they were the anal-receptive partners (35\%) was slightly higher than those who said they were the insertive partners (29\%).

Table 3. Distribution of MSM respondents according to selfreported current sexual identity, Philippines, 2010.

\begin{tabular}{lcc}
\hline Current sexual identity & Frequency & Percent \\
\hline Homosexual & 328 & 48.1 \\
Bisexual & 334 & 48.9 \\
Trans-sexual & 2 & 0.3 \\
Transgender & 7 & 1.0 \\
Heterosexual/Straight & 10 & 1.5 \\
No Response & 1 & 0.2 \\
TOTAL & 682 & 100 \\
\hline
\end{tabular}

The mean number of male sex partners in the last six months was $7(\mathrm{SD} \pm 9.20)$. Some $23 \%$ of the respondents had only one sex partner, while one-third (32\%) had two to four male sex partners and almost one in five $(17.2 \%)$ had five to nine male sex partners. The reported number of male sex partners varied from as few as one to as many as 80 in the last six months (Table 4). Some (14\%) respondents also had female sex partners in the past 12 months. Of the 95 MSMs who had female sex partners, $83 \%$ engaged in vaginal sex but only $52 \%$ reported condom use during their last sexual intercourse with female partners.
Table 4. Distribution of MSM respondents according to the number of male sex partners in the last six months, Philippines, 2010.

\begin{tabular}{lcc}
\hline No. of male sex partners & Number $(\mathrm{n}=682)$ & Percent \\
\hline 1 & 155 & 22.7 \\
$2-4$ & 222 & 32.5 \\
$5-9$ & 117 & 17.2 \\
$10-15$ & 67 & 9.8 \\
$16-19$ & 4 & 0.6 \\
$20-29$ & 49 & 7.2 \\
30 or more & 22 & 3.2 \\
No response & 46 & 6.7 \\
Range & $79(1$ to 80$)$ & \\
Mean (SD) & $7(9.20113)$ & \\
Median & 3 & \\
\hline
\end{tabular}

The respondents obtained condoms from a wide range of sources (Table 5). The most common sources were pharmacies (67\%), and supermarkets (51\%). About one-fifth $(22 \%)$ obtained their condoms from friends and relatives. Less than $10 \%$ of the respondents got condoms from public or private health providers/facilities.

Figure 3 shows the multiple and overlapping risk behaviours of the MSM respondents. Since respondents have relatively low levels of knowledge about HIV/STI, this makes them more vulnerable to engage in practices that increase their risk of HIV infection. Aside from low condom use, alcohol and illegal drug use, high-risk sexual practices also include buying and selling sex with male and/or female

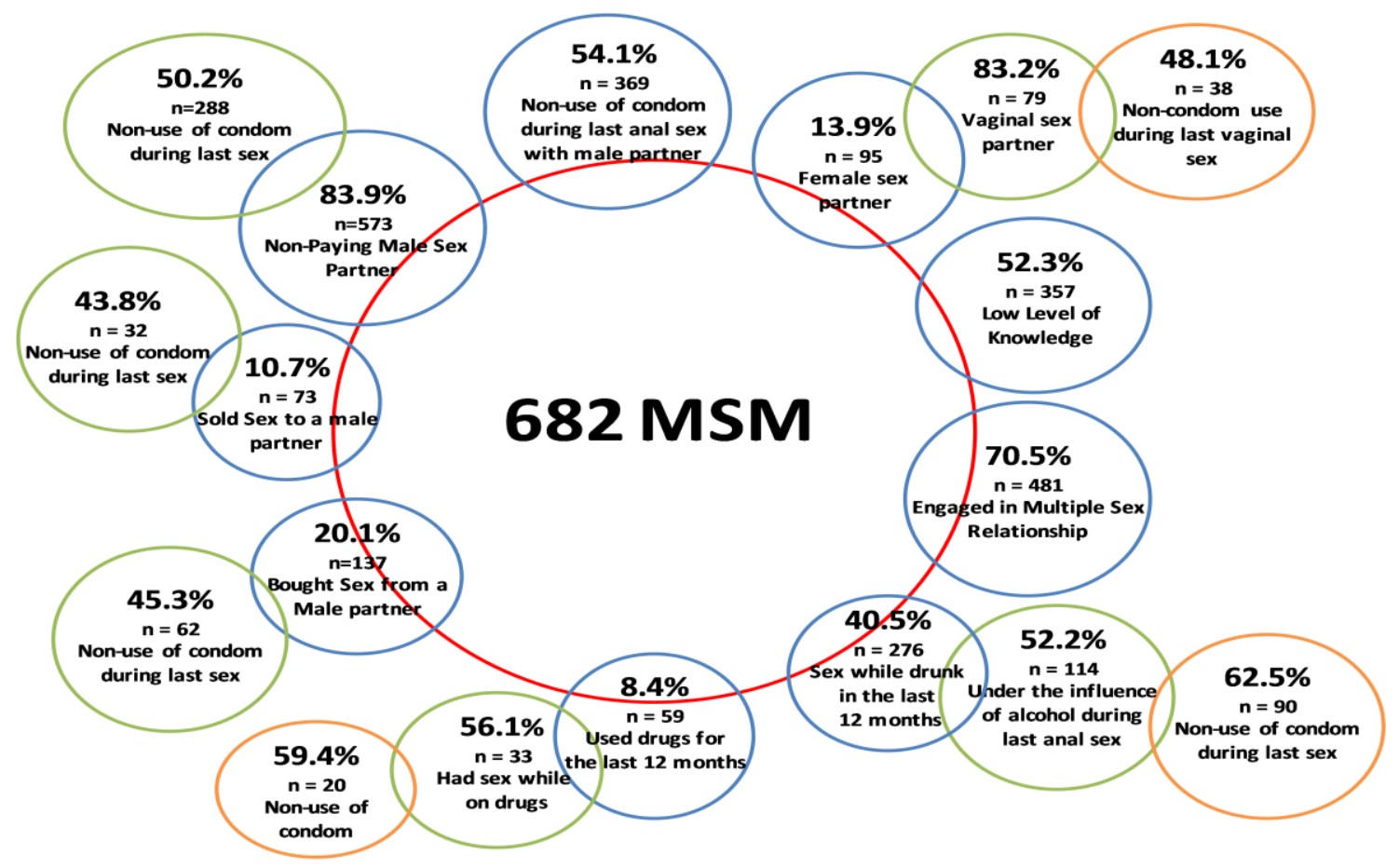

Figure 3. Summary of the HIV risks and vulnerabilities of the MSM study population 
sex partners. In most of these high-risk sexual encounters, condoms were not used. It is important to note that of the three overlapping types of male partners, majority of the respondents had multiple non-paying male sex partners $(83.9 \%)$ and the highest percentage (50\%) of non-condom use can be found in this category (regular/casual partners). Moreover, sex partners of the respondents can be drug users or injecting drug users themselves, and this, in turn, adds another layer of risk to MSMs.

Table 5. Sources of condoms of MSM respondents, Philippines, 2010.

\begin{tabular}{lcc}
\hline \multicolumn{1}{c}{ Source* $^{*}$} & $\begin{array}{c}\text { Frequency } \\
\text { (n = 682) }\end{array}$ & Percent \\
\hline Pharmacy & 457 & 67.0 \\
Supermarket & 350 & 51.3 \\
Friends/Relatives & 151 & 22.1 \\
Bars/Nightspots & 45 & 6.6 \\
'Botika sa Barangay'** & 25 & 3.6 \\
NGO & 24 & 3.5 \\
City Health Office & 17 & 2.4 \\
Private Hospital/Clinic & 15 & 2.2 \\
Private Doctor/Nurse/Midwife & 11 & 1.6 \\
Government Hospital & 8 & 1.2 \\
*Multiple response; **Small village pharmacy & & \\
\hline
\end{tabular}

When asked why condoms were not used during the sex encounters, almost $40 \%$ of the respondents said that condoms were not available and about a third believed that condoms were not necessary (31\%) (Table 6). A quarter said they forgot to use condoms and $20 \%$ of the respondents did not use condoms because they did not like condoms.

Table 6. Respondents' reasons for not using condoms with male sex partners, Philippines, 2010.

\begin{tabular}{lcc}
\hline Reasons for non- use of condom & Number & Percent \\
\hline Not available & 140 & 37.9 \\
Didn't think it was necessary & 115 & 31.2 \\
Didn't think of it (Forgot to use it) & 96 & 26.0 \\
Didn't like condoms & 83 & 22.5 \\
Partner objected & 55 & 14.9 \\
Too expensive & 4 & 1.1 \\
\hline
\end{tabular}

"Multiple response

The attitudes of MSMs toward condom use were assessed by asking their reactions to four statements about condom use. An equal proportion (89.4\%) agreed with the statements, "The use of condoms would reduce the chance of HIV infection from anal sex with same sex partners," and, "The chance of contracting HIV is very high when having anal sex without using condoms." Approximately 29\% agreed that "The use of condoms during sex is not necessary because it decreases sexual pleasure," while only 67/682 respondents agreed with the statement, "Since most of your peers do not use condoms when having sexual intercourse, then you will also not use condoms." Over-all, majority of the MSM respondents had positive attitudes toward condom use (Figures not shown).
Attitudes of the respondents towards having multiple sex partners can be classified into two main categories: (1) to satisfy a personal need, and (2) to justify why they do it (Table 7). Engaging in sex with multiple partners is considered pleasurable and gratifying. It is not uncommon to hear members of this population bragging to each other about the many sex partners that they currently have (or had in the past). A few of the vignettes below reflect some of these sentiments:

"When I am not personally satisfied with my partner, when
I don't enjoy my partner then I go look for others."
"For me, having multiple sex partners is nothing. Among
my friends, we tease each other and we all compete who has
the most number of partners. The one with the highest
number of partners is the 'reyna'(queen)."

Table 7. Attitudes of MSM respondents on having multiple sex partners, Philippines, 2010

\begin{tabular}{lcc}
\hline Attitudes on multiple sex partners* & $\begin{array}{c}\text { Number } \\
\text { (n=682) }\end{array}$ & Percent \\
\hline (1) To satisfy a personal need & 362 & 53.1 \\
Sexually-satisfying & 362 & 53.1 \\
Result of high 'libido' & 317 & 46.5 \\
Self-satisfying & 111 & 16.3 \\
Empowering & 97 & 14.2 \\
Deprived of sexual needs during youth & 80 & 11.7 \\
Partner is too busy or always away & 54 & 7.9 \\
A form of 'revenge'/'payback'/ result of anger & 47 & 6.9 \\
Current partner is 'not good' in bed & 23 & 3.4 \\
Way to earn money & 2 & 0.3 \\
To relieve stress & & \\
(2) To justify why they do it & 137 & 20.1 \\
Common among MSM & 115 & 16.9 \\
Influenced by peers/friends & 109 & 15.9 \\
In an 'open' relationship & & \\
*Multiple response &
\end{tabular}

*Multiple response

Table 8 shows the distribution of respondents according to their personal risk assessment for having HIV infection. Approximately half $(50.9 \%)$ of the respondents considered themselves at risk for HIV. The 347 respondents who felt at risk ranked their risk on a scale of 1 to 5 , with 1 corresponding to very low risk and 5 to very high risk. About 65 MSMs rated their risk 1, i.e., they have very low risk. Only a small proportion (3\%) rated their risk 5, meaning, they considered themselves at very high risk. The main reason for having an increased risk for HIV infection was nonuse or inconsistent use of condoms (66\%). More than half had multiple sex partners (Table 9). On the other hand, for the remaining 324 respondents who perceived themselves at low risk for acquiring HIV, the major reason cited by around 52\% was the belief that their 'partners were clean' followed by a smaller proportion who 'always used condoms' $(36.4 \%)$. It is important to note that only 5 
respondents perceived themselves to be not at risk for HIV because they had checked their HIV status, i.e., they underwent HIV testing (Table 10).

Table 8. Distribution of MSM Respondents According to Personal Assessment of Risk for HIV Infection, Philippines, 2010.

\begin{tabular}{lcc}
\hline Feels at risk for HIV infection? & Frequency $(\mathbf{n}=\mathbf{6 8 2})$ & Percent \\
\hline Not at risk & 324 & 47.5 \\
Magnitude of risk & 347 & 50.9 \\
5 (Very high) & 21 & 3.1 \\
4 (High) & 36 & 5.3 \\
3 (Moderate) & 101 & 14.8 \\
2 (Low) & 87 & 12.8 \\
1 (Very low) & 65 & 9.5 \\
No response & 11 & 1.6 \\
\hline
\end{tabular}

Table 9. Distribution of MSM Respondents According to Perceived Reasons for Feeling at Risk for HIV Infection, Philippines, 2010.

\begin{tabular}{lcc}
\hline \multicolumn{1}{c}{$\begin{array}{c}\text { Reasons for feeling at risk for HIV } \\
\text { infection (Multiple Response) }\end{array}$} & $\begin{array}{c}\text { Frequency } \\
(\mathbf{n}=\mathbf{3 4 7})\end{array}$ & Percent \\
\hline Do not always use condoms & 230 & 66.3 \\
Many sex partners & 207 & 56.7 \\
Had sex with an HIV (+) partner & 20 & 5.8 \\
Already have HIV & 7 & 2.0 \\
Experienced HIV/STI symptoms & 4 & 1.2 \\
Sharing needles when injecting drugs & 1 & 0.3 \\
\hline
\end{tabular}

Table 10. Distribution of MSM Respondents According to their Perceived Reasons for Not Feeling at Risk for HIV Infection, Philippines, 2010.

\begin{tabular}{lcc}
\hline $\begin{array}{c}\text { Reasons for NOT feeling at risk for HIV } \\
\text { infection (Multiple Response) }\end{array}$ & $\begin{array}{c}\text { Frequency } \\
(\mathbf{n = 3 2 4 )}\end{array}$ & Percent \\
\hline Convinced that partner is clean & 170 & 52.5 \\
Always use condoms & 118 & 36.4 \\
Only have one partner & 111 & 34.2 \\
Never do anal sex & 38 & 11.7 \\
Never injected/shared needle & 15 & 4.6 \\
Respondent had checked his HIV status & 5 & 1.5 \\
Partner is a health worker & 1 & 0.3 \\
\hline
\end{tabular}

The major source of information of MSMs (Table 11) on HIV/STIs is the internet (81\%) followed by magazine/newspaper/books (72\%), television (68\%), and printed materials (54\%). For MSMs, the least likely sources of information on HIV/STI were counsellors (26\%) and family or relatives $(21 \%)$.

The health-seeking behaviour of MSMs can be further characterized by their experience with HIV testing and STI treatment. Majority (67\%) had never been tested for any sexually transmitted infection (STI). Only a small number of respondents (18\%) admitted having been treated for any STI. A significant percentage of the population had never undergone HIV testing (72\%). Very few MSMs had been tested for HIV and know their test results (17\%) (Table 12).
Table 11. Distribution of $\mathrm{msm}$ respondents according to sources of information on hiv/sti, philippines, 2010.

\begin{tabular}{lcc}
\hline Source of information on HIV/STI* & $\begin{array}{c}\text { Number } \\
\text { (n=682) }\end{array}$ & Percent \\
\hline Internet & 551 & 80.8 \\
Magazine/Newspaper/Books & 488 & 71.6 \\
Television & 465 & 68.2 \\
Printed Materials (flyers, brochures, posters) & 369 & 54.1 \\
Teachers & 316 & 46.3 \\
Peers & 309 & 45.3 \\
Radio & 216 & 31.7 \\
Counsellors & 178 & 26.1 \\
Family/Relatives & 147 & 21.6 \\
\hline *
\end{tabular}

${ }^{*}$ Multiple response

Table 12. Distribution of MSM respondents according to experience with HIV testing, Philippines, 2010.

\begin{tabular}{lcc}
\hline Had HIV test and know test result & Number $(\mathbf{n}=\mathbf{6 8 2})$ & Percent \\
\hline Had no HIV test & 493 & 72.3 \\
Had HIV test and know test result & 119 & 17.4 \\
Had HIV test but did not know result & 13 & 1.9 \\
No Response & 57 & 8.4 \\
\hline
\end{tabular}

In terms of health services received by MSMs, only $30.9 \%$ of them received information on HIV/STI prevention during their last visit to a health facility. More than half $(76 \%)$ did not receive free condoms; only $14 \%$ were given condoms by health workers. Majority (77\%) were not given counselling on HIV/STI during their last visit to any health facility (Table 13).

Table 13. Distribution of MSM respondents according to whether they had received HIV/STI information and related services from any health facility, Philippines, 2010.

\begin{tabular}{lcc}
\hline Received any of the three services & Number $(\mathbf{n}=\mathbf{6 8 2})$ & Percent \\
\hline Had received information on HIV/STI & prevention? & \\
Yes & 211 & 30.9 \\
No & 410 & 60.1 \\
No Response & 61 & 8.9 \\
Was given condoms? & & \\
Yes & 96 & 14.1 \\
No & 522 & 76.5 \\
No Response & 64 & 9.4 \\
Given counselling on HIV/STI? & & \\
Yes & 97 & 14.2 \\
No & 524 & 76.8 \\
No Response & 61 & 8.9 \\
\hline
\end{tabular}

\section{Discussion}

\section{Heterogeneity of the MSM population}

Men who have sex with men comprise a population with diverse cultures. The preference for male sex partners is not unique to a particular MSM group. Homosexuals/gay men ('bakla'), bisexuals ('silahis'), transgenders (or crossdressers), transsexuals, and even some heterosexuals (or 'straight' men) may be classified as 'MSM'.7,18 Their selfreported identities should be taken at face value because 
there is no method to verify these information. Sexual identity may be different from sexual preference, which again may be different from their actual sexual practices as shown by the results of the current study. The difficulty that characterizing MSMs presents make it hard to conduct researches which in turn impede the development of health programs. Understanding the population is very important. Using the internet allowed a more representative sample of MSMs from all regions of the country to participate in the survey. This is one of the strengths of this study.

\section{Knowledge on HIV transmission and prevention}

The UNGASS knowledge indicators were used to standardize the data and to allow comparison with studies done here and in other countries. The findings show that the extent to which education strategies reach the target population is still limited. Fifty percent of the respondents continue to have low levels of knowledge on HIV prevention and control and those who are more knowledgeable about HIV did not automatically translate these facts to safer sex practices. This finding is the same as those reported by other investigators in low to middle income countries. $16,17,20$ However, the UNGASS questions are limited in that these indicators are factual knowledge questions and do not include the individuals' beliefs regarding HIV prevention and risk assessment, types of partner and HIV status of partners, or the relationships between risky and protective behaviours. ${ }^{20}$ The importance of educating MSMs, e.g. on the correct modes of transmission of HIV, cannot be emphasized enough. MSMs who are not well-informed on HIV/AIDS will not be able to accurately access their own risk for acquiring HIV and take the necessary safety measures.

\section{Sexual Practices of MSMs}

The types of sexual acts most MSMs in this study practiced were oral and anal sex. However, between the two types, the greater concern lies with anal sex since the higher risk for acquiring STI's and ultimately HIV is associated with anal sex, particularly anal-receptive sex. The WHO and UNAIDS confirm that the risk further increases with noncondom use if one of the sexual partners is HIV positive. ${ }^{14,15}$ Moreover, the role an MSM engages in during the sexual act appears to be influenced by many factors especially those factors coming from within the relationship suggestive of power play.

MSMs also have multiple male sex partners. A similar study in Hong Kong found that MSMs who practice anal sex are much more likely to have three or more male partners in the preceding six months, believe that their partners have other male sex partners, and to have engaged in unprotected sex in the last six months. ${ }^{16}$ Insight on this behavior through focus group discussions explained the reasons behind having many male sex partners. MSMs consider this practice as sexually satisfying. It is an affirmation that the individual is attractive and desirable. It may also be a result of their search for love and long-term relationships.

The sexual networks of MSMs are not confined to having different male partners. These extend to the female population. A smaller proportion engages in unprotected vaginal sex with their partners. MSMs can serve as a "bridge group" in the Philippines. A Cambodian research on MSM sexual behaviours considered MSMs as the higher risk population that can link HIV to the general population. ${ }^{17}$ This information should be considered when designing programs for MSMs.

Another contributory factor in the rise of HIV prevalence is the low use of condom despite MSMs having multiple sex partners. Several factors appear to play a role in influencing condom use. Unavailability of condoms remains the main reason for its non-use, despite the existence of programs for HIV/STI prevention in the Philippines that prioritize the accessibility of condoms. This study confirms what other surveys done by the UNAIDS, IHBSS and the FHI (Family Health International) have also found. ${ }^{4,18,19}$ In the country, unprotected sexual intercourse is the leading mode of transmission (90\%) compared to other modes of HIV transmission such as injecting drug use. ${ }^{3}$ Qualitative data show that the stigma attached to the act of buying from drugstores or convenience stores is one major obstacle to improving access of MSMs to condoms. The second issue is the lack of consistency of many respondents in bringing condoms with them constantly. It can be because the furtive and hurried circumstances in which sex is performed does not allow for negotiation of condom use. ${ }^{18}$

Similarly, the type of sex partner influences condom use. Majority of the respondents' male sex partners were non-paying partners. This is comparable to the results obtained by the 2007 IHBSS of the Department of Health. ${ }^{4}$ Non-paying partners include regular sex partners and casual sex partners. The survey, however, was unable to probe as to the possible reasons why type of partner affects condom use. Focus group discussions, on the other hand, were able to substantiate the survey data. For MSMs, the perception that "condom use is not necessary" pertains to regular partners including lovers/boyfriends and "Fuck Buddies" ('FUBU'). The concept of trust and love plays an important role with non-paying partners. Respondents would never use condoms with their regular partners, but would be willing to use condoms with their casual sex partners. Furthermore, condom use is more frequent with paid sex partners than with paying sex partners. The concept of power play may be involved. The person who buys sex (i.e. the client), or the partner with money, good looks, experience, and perceived by the partner as more aggressive often decides whether or not condom will be used.

Attitudes of MSMs and knowledge on condom use can likewise influence their decision on whether or not condom will be used during the sexual act. However, even with 
positive attitudes toward condom use and high levels of awareness among the study respondents on its benefits, these do not ensure the presence of right practices or behaviours.

Alcohol and drug use are two lifestyle behaviours that may increase an MSMs risk of acquiring STI including HIV. Of the two, alcohol use is the most common. The study has shown that more than half of the respondents who used illicit drugs or alcohol while engaging in sexual practices did not use condom. MSMs are more likely to engage in risky sexual practices under the effects alcohol and drugs, particularly in unprotected sex, since these substances take away all their inhibitions and increase their libidos. The use of drugs, particularly injecting drug, further magnifies their risk for HIV because injecting drugs is a major transmission route for HIV transmission especially if used/contaminated needles/syringes are shared between users. However, the researchers were unable to determine the prevalence of injecting drug use among MSMs.

The study attempted to put in perspective the data on these practices by assessing condom use, the types of sexual acts and partners, the number of male partners with whom anal sex is practiced, the role alcohol and drug use play. The variables used to assess the different sexual practices of MSMs (e.g. time period for last anal sex) were patterned after recognized standards such as the IHBSS to improve external validity and allow consistency of the results with the data available internationally and locally. The goal is to achieve adequate understanding of the risky and protective behaviours that MSMs, in general, have. Because although enhancing knowledge on HIV among MSM is still necessary, behaviour change communication initiatives may be more important. Adequate knowledge allows MSMs to make more informed decisions, but knowledge alone does not ensure adoption of safe behaviours.

\section{Sources of Information on HIV/STI}

Review of literature has shown an evolving trend with regard to the major sources of information on HIV/STI. A decade ago, the major sources cited by MSMs were the media, particularly the television, followed by newspapers and other printed materials. ${ }^{19}$ Based on the data of the current study, the major source of information on HIV/STI is now the internet. However, it is important to note that this may be attributed to the fact that all the study respondents are computer literate. Therefore, there may be bias present. Nevertheless, the findings of this research can be verified by studies conducted in other countries. ${ }^{9,10}$ These researches consider the internet as an emerging and potentially powerful influence on health. ${ }^{9,10}$ Many MSMs use the internet because it provides them with anonymity and security. Most of the respondents became aware of HIV/STI through MSM websites which offer information and forums for discussions on HIV, safe sex and sexual practices such as condom use. Prevention programs can utilize the internet as a way to promote health services through IEC strategies, such as disseminating a list of VCT (Voluntary Counselling and Testing) centers at official websites of the Philippine Department of Health.

\section{Utilization of Health Services}

Given the many risky practices of MSMs and their low levels of protective behaviours, it is alarming to note that their health-seeking behaviour, such as getting tested for HIV and going to health centers for treatment of STIs, remains poor. According to a local study on Filipino MSMs, self-medication seems to be their main health-seeking behaviour. ${ }^{5}$ Very few respondents have been tested for HIV; and, still fewer MSMs who have been tested know their results. Many factors are involved as to the reasons why they do not want to be tested for HIV. In the Philippines, HIV testing is not mandatory. There is stigma attached to HIV/STI testing and fear of discrimination inhibits MSMs from availing of this test. Yet, the importance of knowing the test result cannot be emphasized enough because an MSM who is aware that he's HIV positive can seek treatment and take the necessary precautions stop HIV transmission.

Aside from the poor health-seeking behaviour of MSMs, only a small proportion of this population have received health services, i.e., received counselling, received condoms and/or received information on HIV/STI prevention. Comparing the figures of the current study to those of the IHBSS, there has been no improvement in the coverage of these services. ${ }^{4}$ In addition, respondents who have access to government health services are dissatisfied with the health personnel and the method by which the services are delivered, e.g. how counselling is performed and the setting where this is done. It explains why many MSMs are discouraged from accessing VCT. MSMs still consider confidentiality as an important factor when they seek counselling on HIV and STI. Some of the respondents also lacked information as to where they could obtain health services. This poses a great problem for HIV prevention programs such as the surveillance efforts of the Health Department to monitor the coverage and the quality of health services utilized by the target population.

Since the results of this study have shown that respondents have poor health-seeking behaviour and have poor access to services, it is necessary to determine why the utilization of health services is low, i.e., what impedes MSMs from seeking such services, how can services be improved, and how can MSMs be educated on the importance of prioritizing their health. According to one study, to be optimally effective, a comprehensive response is needed to ensure the availability and acceptability of effective HIV prevention programs and to address social exclusion and other structural factors that increase the vulnerability of MSM in low to middle income countries to HIV infection..$^{20}$ 


\section{Conclusions and Recommendations}

MSMs are vulnerable and at high risk for HIV and STI's due to behaviours such as low condom use, alcohol and illicit drug use, and, engaging in sex with multiple partners. This population also remains hard-to-reach, and hence, is difficult to reach by health services for HIV/STI prevention and control. The study also showed that there exists a wide gap between knowledge and actual sexual practices. Despite the presence of these risk factors, MSMs continue to have poor utilization of health services, especially for HIV prevention. Currently, only a small percentage can avail of HIV/STI testing and treatment. It appears that MSMs have limited access to appropriate health services. In the light of the results of this study, there appears to be a need for programs that are tailored to the needs, cultural diversities and unique characteristics of the different MSM subpopulations. The investigators recommend the improvement of IEC programs and the inclusion of targeted BCC (Behavioural Change Communication) interventions.

This study has also demonstrated the feasibility of conducting a study among a marginalized hard-to-reach population with generally a wide coverage of MSMs at a much lower cost. Thus, the internet is recommended not only as a method of data collection but also as a means for reaching out to a wide group of MSMs to push for BCC interventions that will address the multiple high-risk behaviours unprotected sex, multiple sex partners and, alcohol and drug use. The websites can provide the names and addresses of agencies which provide information and services for HIV/STI prevention. Websites can be used as discussion venues for exchange of information and, possibly, for counselling.

Non-government organizations have an important role to play in complementing the services of the government in reaching out to MSM subpopulations who could not be reached through the mainstream information and services. The services of the VCTs should be promoted by both government and private agencies working with MSM populations.

\section{Acknowledgments}

The authors would like to thank the following persons and institutions who assisted us in various stages of our research. Mr. Joel A. De Mesa helped us conceptualize and implement the qualitative data collection. Mr. Marasigan and some of the staff of the Library Foundation assisted us in the conduct of an FGD with the target population. Ms. Noemi Bayoneta-Leis and Ms Emie de Vera of Health Action Information Network (HAIN) provided us with useful references. Mr. Orlando Red and Mr. Glenn Cruz allowed us to access our target population through the websites they administer. The staff of the Department of Epidemiology and Biostatistics, College of Public Health, UP-Manila gave us technical and moral support throughout the implementation of the study.

\section{References}

1. National Epidemiology Center. HIV and AIDS Registry. National Epidemiology Center, Department of Health, Manila, Philippines, 2014.

2. National Epidemiology Center. IHBSS National Dissemination Forum. National Epidemiology Center, Department of Health. Manila, Philippines, 2009.

3. Philippine National AIDS Council. Country Report of the Philippines January 2003 - November 2005. Manila, Philippines, 2006.

4. National Epidemiology Center Department of Health. Integrated HIV Behavioral and Serologic Surveillance Finding. Manila, Philippines, 2009.

5. Hernandez LI, Imperial RH. Men-who-have-Sex-with-other-Males (MSM) in the Philippines - Identities, Sexualities and Social Mobilities: A Formative Assessment of HIV and AIDS Vulnerabilities. Acta Med Philipp. 2009; 43(3):26-36.

6. Tan ML. Survival Through Pluralism: Emerging Gay Communities in the Philippines. The Haworth Press, Inc.; 2001. pp.117-142.

7. Tan ML. From Bakla to Gay: Shifting Gender Identities and Sexual Behaviors in the Philippines. In: Parker RG and Gagnon JH, eds. Conceiving sexuality: Approaches to sex research in a postmodern world. New York: Routledge; 1995. pp.5-96.

8. Pontes Kerr, et al. Self-reported sexual behaviour and HIV risk taking among men who have sex with men in Fortaleza, Brazil. Hagerstown, MD: Lippincott Williams \& Wilkins; 1999.13:709-717.

9. Klein H. Sexual orientation, drug use preference during sex and HIV risk practices and preferences among men who specifically seek unprotected sex partners via the internet. Int J Environ Res Public Health. 2009; 6(5):1620-35.

10. Roztocki N. Using Internet-based surveys for Academic Research: Opportunities and Problems. American Society of Engineering Management (ASEM) National Conference [Online]. 2009. Available from http://www2.newpaltz.edu/ roztockn/alabam01.pdf

11. Council for International Organizations of Medical Sciences. International Ethical Guidelines for Biomedical Research Involving Human Subjects. CIOMS. Geneva, 2002.

12. Hewson MD, et al. Ethics Guidelines for Internet-mediated Research. British Psychological Society [Online]. 2013. Available from http://www.bps.org.uk/system/files/Public\%20files/inf206-guidelinesfor-internet-mediated-research.pdf

13. International HIV/AIDS Alliance. Between Men: HIV/STI prevention for men who have sex with men. United Kingdom: Queensberry House, 2003.

14. Boyce P, Aggleton P, Malcolm A. Rapid Assessment and Response Adaptation Guide on HIV and Men who have Sex with Men. World Health Organization, Geneva, 2004.

15. UNAIDS. Policy Brief: HIV and Sex between Men. UNAIDS, Geneva, 2006.

16. Lau JTF, Kim JH, Lau M, Tsui HY. HIV related behaviours and attitudes among Chinese men who have sex with men in Hong Kong: a population based study. Sex Transm Infect. 2004; 80(6):459-65.

17. Girault P, et al. Sexual Behavior, STIs and HIV among Men who have Sex with Men in Phnom Penh, Cambodia Family Health International, Cambodia, 2000.

18. UNAIDS. HIV and Men who have Sex with Men in Asia and the Pacific. UNAIDS, Geneva, 2006.

19. Jimenez PR, Lee RB. Male sexual risk behavior and HIV/AIDS: A survey in three Philippine cities. Family Health Information IMPACT USAIDS, 2001.

20. Adam PC, de Wit JB, Toskin I, et al. Estimating levels of HIV testing, HIV prevention coverage, HIV knowledge, and condom use among men who have sex with men (MSM) in low-income and middle-income countries. J Acquir Immune Defic Syndr., 2009; 52 Suppl 2: S143-151.

21. PNHRS. National Ethical Guidelines for Health Research. Manila, Philippines. Philippine National Health Research System, 2011. 